\title{
SEASONAL AND ALTITUDINAL VARIATION IN POLLINATOR COMMUNities IN GRAND TETON NATIONAL PARK
}

\author{
Michael E. Dillon $\downarrow$ DEPARTMENT OF ZOOLOGY AND PHYSIOLOGY \\ AND PROGRAM IN ECOLOGY ^ UNIVERSITY OF WYOMING ^LARAMIE
}

\begin{abstract}
$\uparrow \quad$ AbSTRACT
Native pollinators are in decline across the globe, likely due to a combination of habitat loss, pesticides, invasive species and changing climate. Determining the independent effects of climate on pollinators has been difficult in part because we lack studies of pollinator populations in largely undisturbed areas. Early spring and alpine pollinators are most likely to be affected by changing climate. Using a standardized sampling protocol, I measured relative abundance of major pollinator groups (flies, beetles, bees, wasps, and butterflies) from early spring to late summer at sites ranging from 2100 to $3300 \mathrm{~m}$ elevation. Flies were most abundant in early spring and at high elevations. Bees were abundant throughout the season and across all elevations. These data suggest that flies and bees should be targeted for future monitoring because they may be particularly susceptible to changing climate, and their loss could cascade through the broader community.
\end{abstract}

\section{$\uparrow \quad$ INTRODUCTION}

Global warming is likely having profound and diverse effects on organisms, including shifts in their distributions (Parmesan and Yohe 2003) and changes in the timing of life history events ("phenology"; Both et al. 2006). Differential effects of climate on phenology of community members can lead to "phenological mismatches" that may cause reductions or even extinctions of local populations (Memmott et al. 2007). Such phenological mismatches may have played a key role in the decline of insect pollinators in Europe (Biesmeijer et al. 2006) and the Unites States (Cameron et al. 2011) over the last 20-30 years. These pollinator declines are alarming not only because of their effects on agriculture (Berenbaum et al. 2007) and therefore human health (Eilers et al. 2011) but also because of their potentially substantial and far-reaching indirect effects on ecosystem services (over $85 \%$ of flowering plants depend on insect pollination; Ollerton et al. 2011).

Pollinator declines are undoubtedly tied to loss of habitat associated with changes in landscape use (Cameron et al. 2011), to nontarget effects of over- and misuse of common herbicides and insecticides (Henry et al. 2012, Whitehorn et al. 2012), and to pathogen spread from introduced species (Stout and Morales 2009). However, the effect of changing climate on pollinators is less clear because we have so little data on undisturbed pollinator populations (see Parmesan 2007), making it difficult to disentangle the effects on pollinators of climate vs other drivers (reviewed by Potts et al. 2010).

Given that long-term data on pollinator populations in undisturbed locations is rare, one approach to assessing potential impacts of climatedriven phenological mismatch is to identify pollinators whose phenology and life-history make them more likely to be impacted by changing spring temperatures (Memmott et al. 2007). In particular, pollinators that emerge in early spring and specialize on particular plant species may be more susceptible to phenological mismatch (e.g. Kudo et al. 2004). Similarly, pollinators in alpine ecosystems may be particularly vulnerable to changing climate because the short and unpredictable growing season increases the probability of mismatch with floral resources (Burkle and Alarcon 2011), and because mountains 
have experienced the most extreme temperature changes (IPCC 2007). Furthermore, alpine plants are more strongly dependent on pollinators for reproduction (García-Camacho and Totland 2009), making the potential community-wide effects of phenological mismatch pronounced in alpine ecosystems.

Knowledge of seasonal and altitudinal abundances of pollinators in undisturbed habitats provides important data on which groups and species are most likely to be affected by shifting climate. However, community-wide studies of altitudinal and seasonal variation in pollinators are rare (Cruden 1972, Macior 1974, Arroyo et al. 1982, Primack 1983, Inouye and Pyke 1988, Warren et al. 1988). In general, bees tend to dominate the pollinating fauna but often diminish in importance with altitude (Primack 1983, Warren et al. 1988 but see Arroyo et al. 1982), where they are often replaced by flies and butterflies (Macior 1974, Inouye and Pyke 1988). Unfortunately, the limited data available are largely based on non-standardized sampling techniques, making interpretation of the relative abundance data problematic. Therefore, these data are of limited utility for identifying pollinators most at threat from ongoing climate change.

To address this gap, here I report preliminary data on insect pollinator communities in Grand Teton National Park. The study area is attractive because it has remained largely undisturbed in terms of anthropogenic impacts unrelated to climate (e.g. land use changes and agricultural chemicals) and because the large elevation gradient within the park facilitates altitudinal transects. Newly available standardized sampling protocols allow for unbiased assessment of seasonal and altitudinal variation in insect pollinator populations.

\section{$\uparrow \quad$ METHODS}

\section{Study sites}

I sampled pollinators at 13 sites in Grand Teton National Park (GTNP), Wyoming, USA during three separate trips in 2011: June 24 - July 1, July 1623, and August 12-19 (Table 1). One site was near the UW-NPS Research station on the AMK Ranch, five sites were spaced roughly every $250 \mathrm{~m}$ in elevation from 2100-3050 $\mathrm{m}$ along the Paint Brush Canyon Trail and 6 sites were spaced roughly every $250 \mathrm{~m}$ in elevation from 2100 to $3300 \mathrm{~m}$ along the Death Canyon trail (Figure 1, Table 1). All sampling sites were open meadows with abundant flowers. Flower abundance and community composition varied seasonally and with altitude among sites but was not explicitly measured (Shaw 1968 for description of area flora).

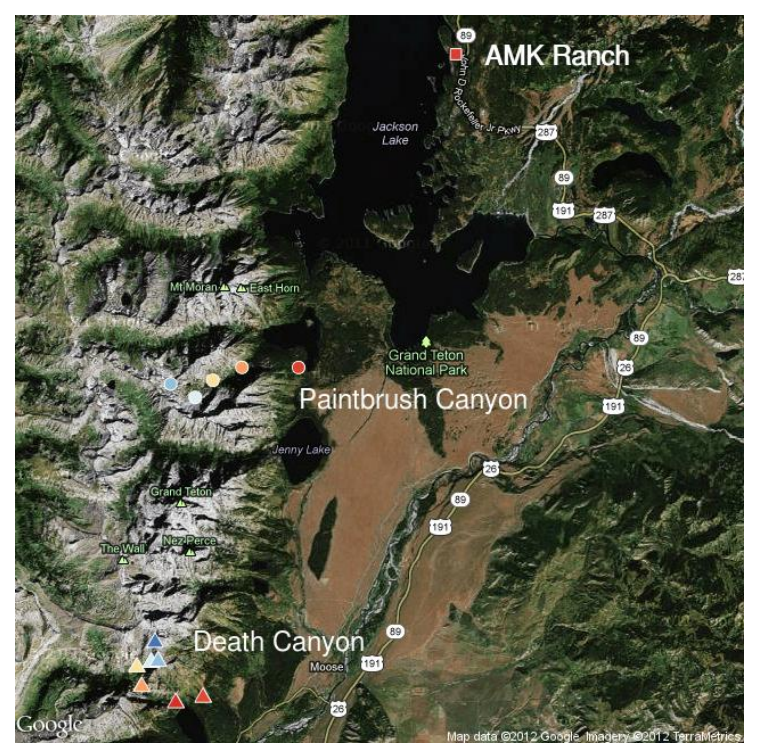

Figure 1. Pollinator collection sites within Grand Teton National Park. Point colors indicate altitude from low (red) to high (blue).

\section{Collections}

At each site, I collected pollinators in bowl traps (Southwood and Henderson 2009), which are an effective, unbiased and standardized method for sampling insect pollinators (Dafni 1992; Berenbaum et al. 2007), including flies, beetles, bees, butterflies, and wasps (Dafni 1993, Berenbaum et al. 2007). Bowl traps were made from $5 \mathrm{oz}$ polystryene vials (40 dram, Thornton Plastic Co., Salt Lake City, Utah, USA) painted white, fluorescent yellow, and fluorescent blue, colors that are attractive to a diverse assortment of pollinating insects (Dafni 1993). Bowl triplets (one of each color) were mounted on rebar stakes at approximately the height of the surrounding flowers (10-40 cm above ground). Stakes were placed in a straight line roughly $6 \mathrm{~m}$ apart to avoid effects of neighboring bowls on capture rates (Droege et al. 2010). Bowl traps were filled $\sim 3 / 4$ full with soapy water ( 1 tsp. Dawn Original Blue ${ }^{\circledR}$ dish soap per gallon distilled water) to minimize surface tension and therefore maximize captures of visiting insects. Bowls were left out for a $\sim 48$ hour sampling period before cup contents were poured through coffee filters to separate collected insects for transport to the lab. In the lab, collections were sorted by taxonomic group and counted, using a binocular scope when necessary. All collections were done under permit GRTE-2011-SCI-0011 (Study \# GRTE00219). 
Table 1. Pollination sampling sites.

\begin{tabular}{lllll|}
\hline Site & Location & Elevation $(\mathrm{m})$ & \multicolumn{1}{c|}{ Description } \\
\hline AM2100 & 43.9359 N, 110.6369 W & 2087 & Between Leek's marina and UWNPS research station \\
DC2100 & $43.6537 \mathrm{~N}, 110.8057 \mathrm{~W}$ & 2050 & Death Canyon trail SW of junction with Phelps lake trail \\
DC2350 & $43.6608 \mathrm{~N}, 110.8264 \mathrm{~W}$ & 2364 & Death Canyon trail below lip before ranger cabin \\
DC2600 & $43.6694 \mathrm{~N}, 110.8292 \mathrm{~W}$ & 2597 & Alaska Basin trail before 5th switchback \\
DC2850 & $43.6713 \mathrm{~N}, 110.8206 \mathrm{~W}$ & 2831 & Alaska Basin trail at 2nd switchback on Albright west slope \\
DC3050 & $43.6720 \mathrm{~N}, 110.8163 \mathrm{~W}$ & 3053 & Alaska Basin trail just before Albright-Static saddle \\
DC3300 & $43.6800 \mathrm{~N}, 110.8183 \mathrm{~W}$ & 3314 & Alaska Basin trail just north of static peak divide \\
PB2100 & $43.7998 \mathrm{~N}, 110.7316 \mathrm{~W}$ & 2103 & Leigh Lake trail past spillway to String Lake \\
PB2350 & $43.7999 \mathrm{~N}, 110.7657 \mathrm{~W}$ & 2358 & Paintbrush Canyon trail just below lower campsites \\
PB2600 & $43.7942 \mathrm{~N}, 110.7832 \mathrm{~W}$ & 2579 & Paintbrush Canyon trail below last shelf before Holly Lake \\
PB2850 & $43.7867 \mathrm{~N}, 110.7940 \mathrm{~W}$ & 2830 & South fork of PB Canyon trail near lake (not Holly) \\
PB3050 & $43.7926 \mathrm{~N}, 110.8089 \mathrm{~W}$ & 3055 & Paintbrush Canyon trail just below Paintbrush Divide.
\end{tabular}

\section{$\downarrow \quad$ PREliminary RESUlts}

During 2011, 6063 hours of sampling (30315 cup hours) yielded 4680 insects. Overall, flies dominated cup collections (67\% of all insects) followed by beetles (21\%), bees (7\%), wasps (4\%), and butterflies making up just over $1 \%$ (Figure 2). The 2011 season was an unusually cold and wet year such that altitudinal representation varied with season and I was unable to reach the highest elevation sites until mid-August (Figure 3). I therefore subset the data to compare pollinator fauna among seasons and altitudes.

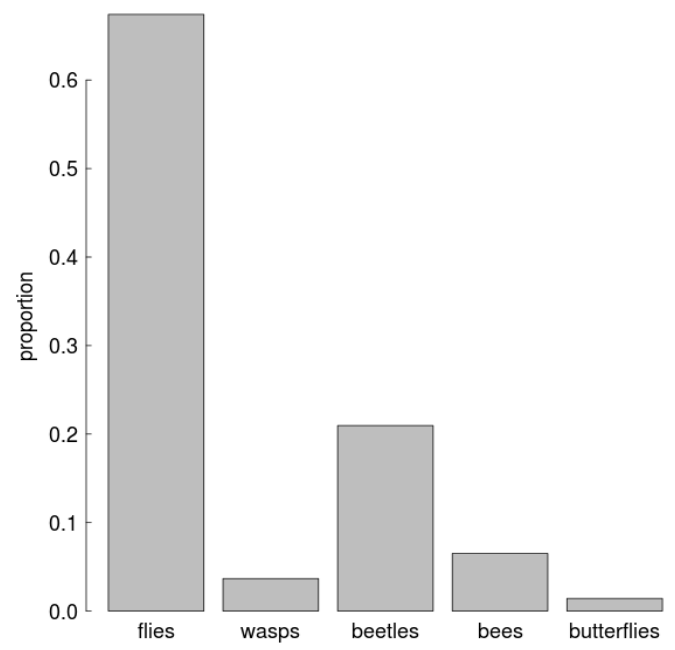

Figure 2. Taxonomic composition of pollinators caught in bowl traps across all sites and sampling periods.

\section{Seasonal variation in pollinator communities}

When the data were restricted to the lowest elevation sites (AM2100, DC2100, PB2100; see Table 1, Figure 3), the number of pollinators captured per cup hour of sampling tended to increase across the season (ANOVA, $P=0.053$ ), but the response varied among sites (ANOVA, interaction effect, $P=0.052$ ), with AMK and Death Canyon having increased catch in August (Figure 4, black and red points) but Paintbrush Canyon showing no seasonal trend (Figure 4, blue points). These low elevation sites were dominated by beetles $(47 \%)$ followed by flies $(32 \%)$, bees $(12 \%)$, wasps $(5 \%)$, and butterflies $(<1 \%)$.

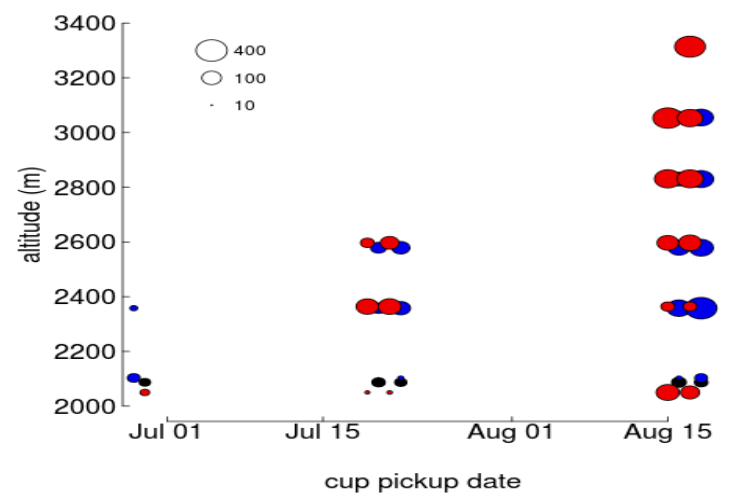

Figure 3. Seasonal and altitudinal sampling during 2011. Points are dates on which cups were collected from sites after 48 hours of sampling. Point color indicates sampling area (black: AMK Ranch, blue: Paintbrush Canyon, red: Death Canyon) and points are scaled by total number of insects collected (see inset legend). 


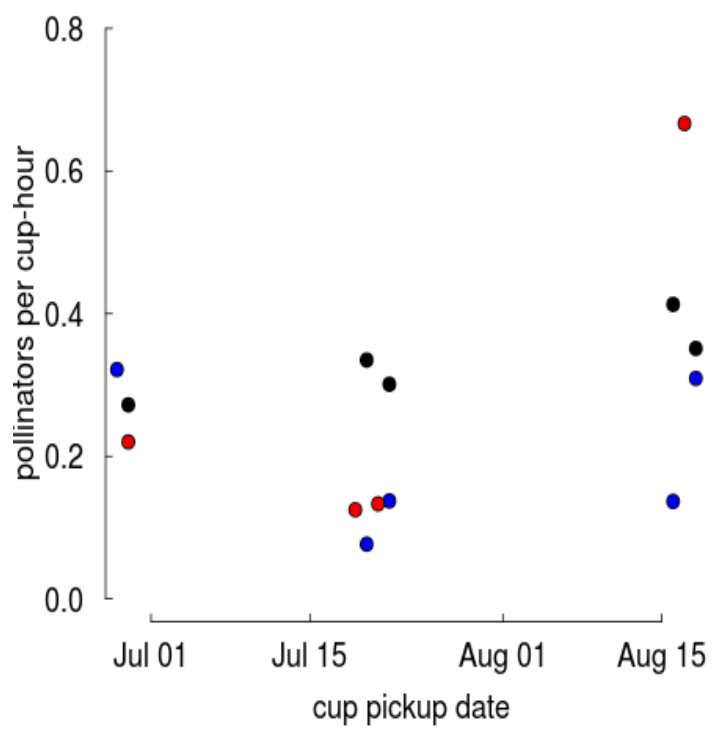

Figure 4. Number of insect pollinators collected per cup hour at low elevation sites (AMK, Paintbrush, and Death Canyon $2100 \mathrm{~m}$; see Figure 3) from early spring to late summer. Colors as in Figure 3.
The pollinator fauna in early spring was dominated by beetles $(45 \%)$, followed by bees $(27 \%)$ and flies $(27 \%)$, whereas in late summer flies $(39 \%)$ and beetles $(38 \%)$ dominated, with bees also accounting for a sizable portion of cup collections (12\%). Wasps and butterflies never accounted for more than $7 \%$ of collections. These seasonal patterns in pollinator community composition were driven by an increase in fly abundance across the season (ANOVA, $P=0.032$; Figure 5A), a marginal decrease in beetle abundance (ANOVA, $P=0.062$; Figure 5B), and no change in bee abundance across the season (ANOVA, $P=0.744$; Figure 5C).

\section{Altitudinal variation in pollinator communities}

Because of limited sampling at high altitudes early in the season (Figure 3), I only compare altitudinal variation in pollinator communities for the late summer sampling dates (Figure 3). Late season samples were dominated by flies $(70 \%)$, followed by beetles $(19 \%)$, bees $(6 \%)$, wasps $(3 \%)$, and butterflies $(<2 \%)$. There was a nonsignificant trend for the total number of pollinators
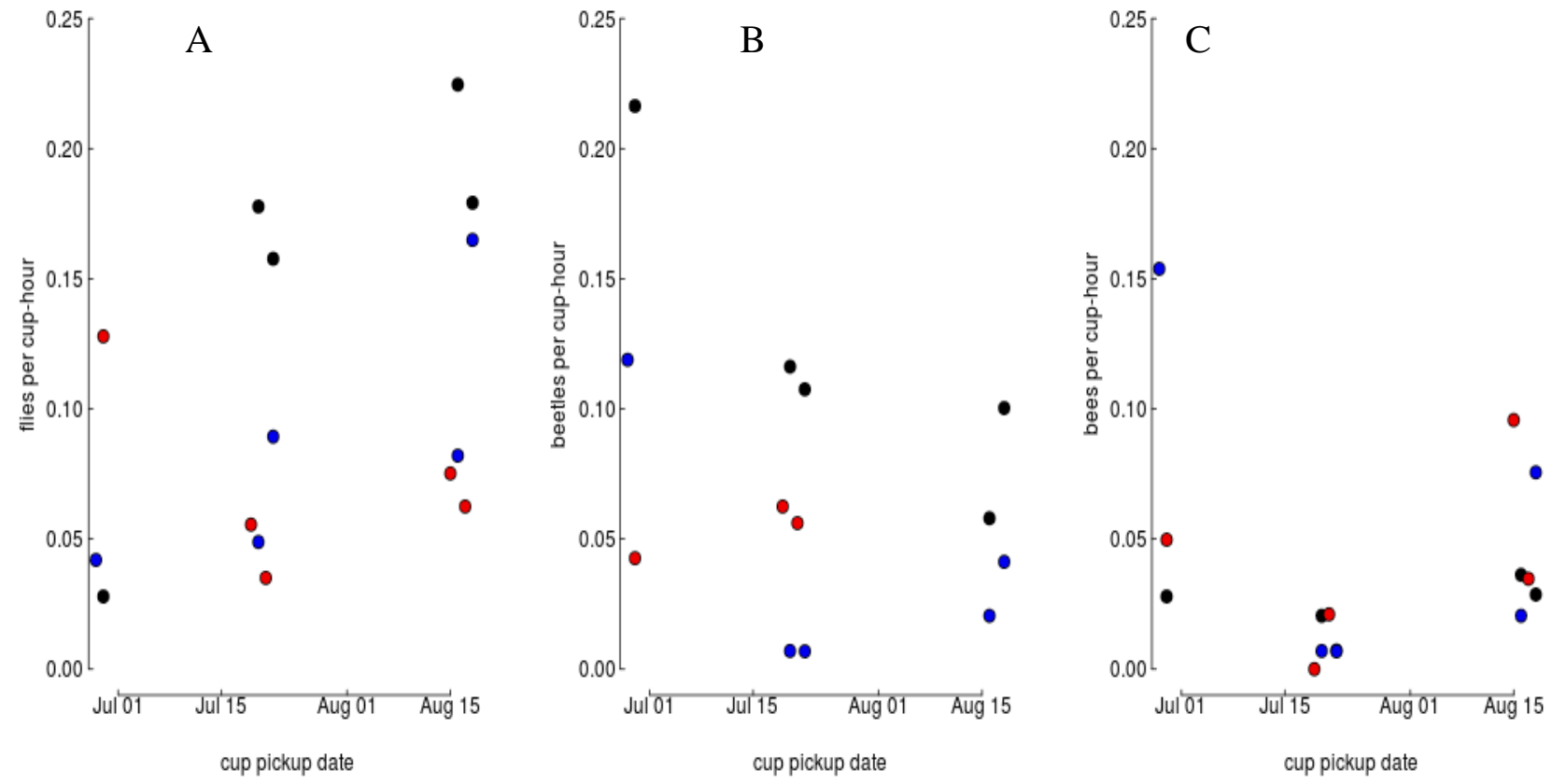

Figure 5. Seasonal changes in abundance of flies (A), beetles (B), and bees (C) at three sites in GTNP (colors as in Figure 3). Wasps and butterflies were also collected but never made up more than $7 \%$ of any collections. 

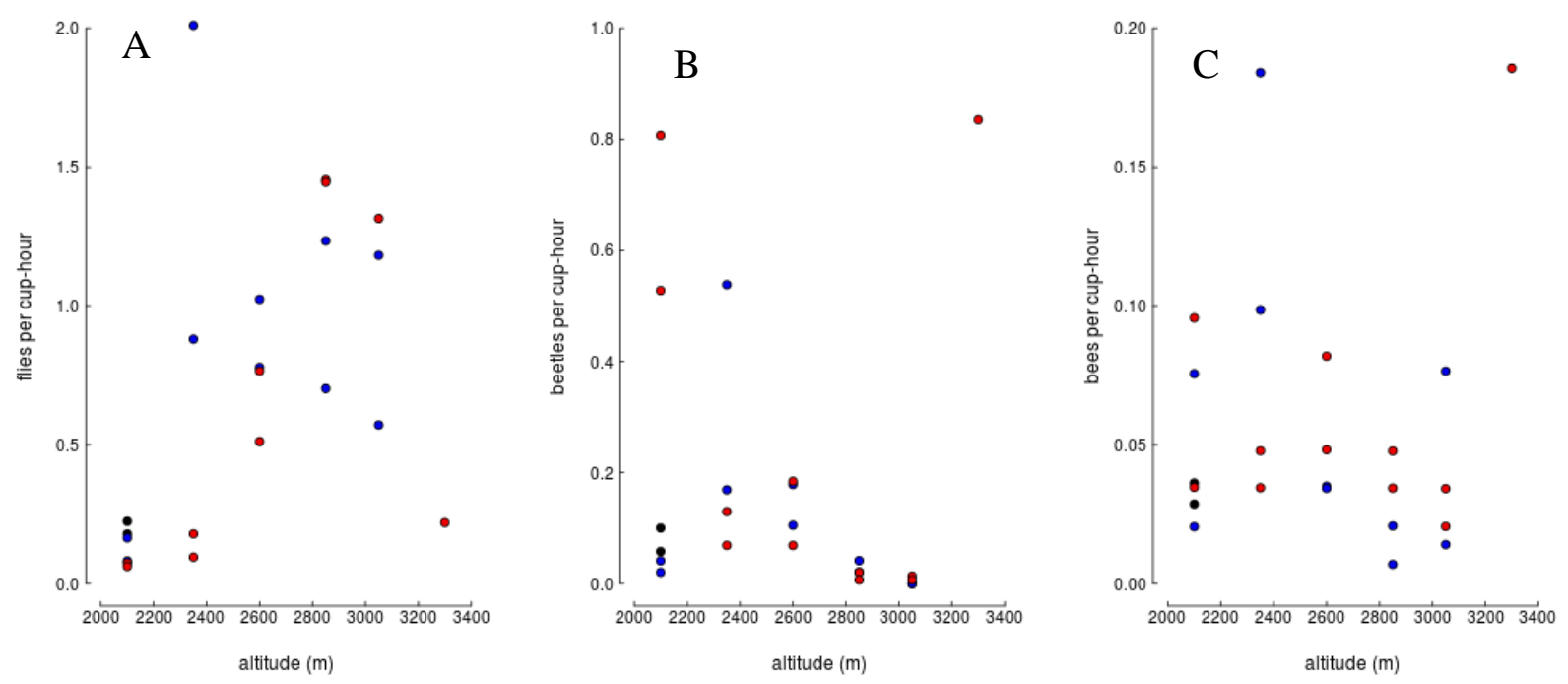

Figure 6. Altitudinal variation in abundance of flies (A), beetles (B), and bees (C) during mid-August in GTNP (colors as in Figure 3). Wasps and butterflies were also collected but never mad up more than $7 \%$ of any collections. Note: y-axes limits vary between plots.

per cup hour to increase with elevation during the final sampling period (ANOVA, $P=0.085$ ). This may be due to the interaction between season and altitude: this was late in the season for the low altitude sites and early to mid season for the high altitude sites. Flies and beetles dominated at $2100 \mathrm{~m} \mathrm{(39 \%}$ and 38\% of captures, respectively), followed by bees (12\%). Mid-elevation (2850-3050 m) sites were $~ 95 \%$ flies. Beetles dominated the $3300 \mathrm{~m}$ site $(64 \%)$, followed by flies $(17 \%)$ and bees $(14 \%)$. These patterns in pollinator community composition were driven by altitudinal increases in flies up to $3050 \mathrm{~m}$ (ANOVA, $P<0.001$ ), altitudinal decreases in beetles (ANOVA, $P=0.003$ ), and relatively constant bee abundances across altitude (ANOVA, $P=0.111$; see Figure 6). Wasps and butterflies were particularly rare at high elevations but never made up more than $7 \%$ of the samples at any elevation.

\section{$\uparrow \quad$ CONCLUSIONS}

Preliminary analyses suggest that flies are under-appreciated pollinators. Not only were flies by far the most abundant pollinators overall (Figure 2), they were proportionately more abundant in early spring (Figure 5) and at high elevations (Figure 6) than the next most common pollinators, beetles and bees. Recent pronounced declines in pollinating flies (Biesmeijer et al. 2006) combined with their prevalence in early spring and at high elevations documented here suggests that flies may be particularly susceptible to changing climate. However, flies tend to be generalist pollinators, able to harvest resources from a wide variety of flowers (Willmer 2011), perhaps buffering them from potential climate-induced phenological mismatch. From the plant perspective, flies often have short dispersal distances and limited capacity to carry pollen (Willmer 2011), potentially making the community-wide implications of reduced fly populations less severe.

Beetles are also common in early spring (Figure 5), but tend to be rare above $2600 \mathrm{~m}$ (Figure 6). However, like flies, they tend to be generalist feeders and (usually) less effective pollinators (Willmer 2011).

Although they can be important pollinators in other systems, wasps and butterflies were always rare in these collections. For butterflies, which are often one of the most common pollinators collected, bowl traps may be an inappropriate sampling technique. The relatively large size of butterflies may make it difficult to capture visitors in the small cups. Butterflies have also been one of the most important groups for documenting the biological effects of changing climate (Parmesan and Yohe 2003), therefore future work should include alternative sampling methods for estimating butterfly populations. 
Although bees were not the most abundant pollinators, they were present in sizable numbers across all seasons and altitudes (Figures 5, 6). Given that: 1) bees are active early in the spring and at high altitudes, 2) that flower specialization is particularly common among bees (reviewed by Willmer 2011), and 3) that bees are effective pollinators of diverse plants then bees may be particularly susceptible to changing climate and reductions in bee populations are likely to reverberate through the broader community.

\section{FUTURE WORK}

Beyond the abundance data presented here, we are also exploring other characteristics of insect pollinators that may change seasonally and altitudinally and that may also alter their importance as pollinators. Body size can vary with geographic and seasonal shifts in temperature (see, Bishop and Armbruster 1999, Brehm and Fiedler 2004, Dillon et al. 2006) and also has important implications for pollinator efficiency and floral specialization. We are currently measuring body size of identified native bee specimens to test for seasonal and altitudinal variation in body size among this diverse group of important pollinators.

\section{ACKNOWLEDGEMENTS}

I thank the UW-NPS Research Station for financial support, my collaborators Carlos Martinez del Rio and Scott Shaw for discussions and advice, Linda Franklin and Sue Consolo-Murphy for facilitating collection permits, John Bruno, Olivia Nater, Christine Bell, and Shelby Oelklaus for help in the field and lab, and Hank Harlow and Celeste Havener for facilitating station arrangements.

\section{$\downarrow \quad$ Literature Cited}

Arroyo MTK, Primack R, Armesto J. 1982. Community studies in pollination ecology in the high temperate Andes of central Chile. I. Pollination mechanisms and altitudinal variation. American Journal of Botany 69:82-97.

Biesmeijer JC, Roberts SPM, Reemer M, Ohlemüller R, Edwards M, Peeters T, Schaffers AP, Potts SG, Kleukers R, Thomas CD, et al. 2006. Parallel declines in pollinators and insect-pollinated plants in Britain and the Netherlands. Science. 313:351-354.
Bishop JA, Armbruster WS. 1999. Thermoregulatory abilities of Alaskan bees: effects of size, phylogeny and ecology. Functional Ecology 13:711-724.

Both C, Bouwhuis S, Lessells CM, Visser ME. 2006. Climate change and population declines in a long-distance migratory bird. Nature 441:81-83.

Brehm G, Fiedler K. 2004. Bergmann's rule does not apply to geometrid moths along an elevational gradient in an Andean montane rain forest. Global Ecology and Biogeography 13:7-14.

Burkle LA, Alarcon R. 2011. The future of plantpollinator diversity: Understanding interaction networks across time, space, and global change. American Journal of Botany 98:528-538. doi: 10.3732/ajb.1000391.

Cameron SA, Lozier JD, Strange JP, Koch JB, Cordes N, Solter LF, Griswold TL. 2011. Patterns of widespread decline in North American bumble bees. Proceedings of the National Academy of Sciences 108:662667. Retrieved July 23, 2012.

Cruden RW. 1972. Pollinators in high-elevation ecosystems: relative effectiveness of birds and bees. Science 176:1439-1440.

Dafni A. Pollination ecology: a practical approach. New York: Oxford University Press; 1993.

Dillon ME, Frazier MR, Dudley R. 2006. Into thin air: physiology and evolution of alpine insects. Integrative and Comparative Biology 46:49-61.

Droege S, Tepedino VJ, Lebuhn G, Link W, Minckley RL, Chen Q, Conrad C. 2010. Spatial patterns of bee captures in North American bowl trapping surveys. Insect Conservation and Diversity 3:15-23.

Eilers EJ, Kremen C, Smith Greenleaf A, Garber AK, Klein AM. 2011. Contribution of pollinatormediated crops to nutrients in the human food supply. PLoS ONE 6:e21363.

García-Camacho R., Totland Ø. 2009. Pollen limitation in the alpine: a meta-analysis. Arctic, Antarctic, and Alpine Research 41:103-111. 
Henry M, Beguin M, Requier F, Rollin O, Odoux JF, Aupinel P, Aptel J, Tchamitchian S, Decourtye A. 2012. A common pesticide decreases foraging success and survival in honey bees. Science 336:348-350.

Inouye DW, Pyke GH. 1988. Pollination biology in the Snowy Mountains of Australia: comparisons with montane Colorado, USA. Australian Journal of Ecology 13:191-205.

IPCC. Climate Change 2007: The Physical Science Basis: Contribution of Working Group I to the Fourth Assessment Report of the Intergovernmental Panel on Climate Change. New York: Cambridge University Press; 2007.

Kudo G, Nishikawa Y, Kasagi T, Kosuge S. 2004. Does seed production of spring ephemerals decrease when spring comes early? Ecological Research 19:255-259.

Macior LW. 1974. Pollination ecology of the Front Range of the Colorado Rocky Mountains. Melanderia 15:1-59.

Memmott J, Craze PG, Waser NM, Price MV. 2007. Global warming and the disruption of plantpollinator interactions. Ecology Letters 10:710-717.

National Research Council (U.S.) Status of pollinators in North America. Washington DC: The National Academies Press; 2007.

Ollerton J, Winfree R, Tarrant S. 2011. How many flowering plants are pollinated by animals? Oikos 120:321-326.

Parmesan C. 2007. Influences of species, latitudes and methodologies on estimates of phenological response to global warming. Global Change Biology 13:1860-1872. Retrieved July 23, 2012, .
Parmesan C, Yohe G. 2003. A globally coherent fingerprint of climate change impacts across natural systems. Nature 421:37-42.

Potts SG, Biesmeijer JC, Kremen C, Neumann P, Schweiger O, Kunin WE. 2010. Global pollinator declines: trends, impacts and drivers. Trends in Ecology and Evolution 25:345-353.

Primack RB. 1983. Insect pollination in the New Zealand mountain flora. New Zealand Journal of Botany 21:317-334.

Shaw RJ. Field guide to the vascular plants of Grand Teton National Park, Wyoming. Logan, UT: Utah State University Press. 1976.

Southwood TRE., Henderson PA. Ecological Methods, 3rd edition. Hoboken, NJ: WileyBlackwell; 2009

Stout JC, Morales CL. 2009. Ecological impacts of invasive alien species on bees. Apidologie 40:388-409.

Warren S, Harper K, Booth G. 1988. Elevational distribution of insect pollinators. American Midland Naturalist 120:325-330.

Whitehorn PR, O'Connor S, Wackers FL, Goulson D. 2012. Neonicotinoid pesticide reduces bumble bee colony growth and queen production. Science 336:351-352.

Willmer P. Pollination and Floral Ecology. Princeton, NJ; Princeton University Press; 2011. 